\title{
CAUSTIC STRICTURES OF THE OESOPHAGUS
}

\author{
BY \\ PAUL MARCHAND \\ From the Thoracic Surgery Unit and Department of Surgery, University of Witwatersrand, Johannesburg
}

(RECEIVED FOR PUBLICATION MARCH 1, 1955)

In a previous paper (Marchand, 1954) the sociological aspects of caustic soda poisoning in Johannesburg were discussed. That review dealt with 116 cases treated during the four-year period July, 1948, to July, 1952. A second communication (Marchand, 1955) on acute caustic injuries was based upon five years' experience and a total of 152 cases. Between July, 1953, and July, 1954, a further 56 patients have been added, making a total of 208 patients in six years (Table 1). One

TABLE I

ANALYSIS ACCORDING TO RACE, SEX, AND AGE OF ALL PATIENTS (WITH ACUTE INJURIES OR WITH ESTABLISHED STRICTURES) ADMITTED TO THE THORACIC SURGICAL UNIT AT TWO HOSPITALS DURING SIX YEARS

\begin{tabular}{|c|c|c|c|c|c|}
\hline & & \multicolumn{2}{|c|}{ Adult } & \multirow{2}{*}{$\begin{array}{c}\text { Child } \\
\text { (Under } \\
14 \text { Years) }\end{array}$} & \multirow{2}{*}{ Total } \\
\hline & & Male & Female & & \\
\hline $\begin{array}{l}\text { Europeans } . . \\
\text { Coloured } \\
\text { Asian } \\
\text { African }\end{array}$ & $\begin{array}{l}\cdots \\
\cdots \\
\cdots\end{array}$ & $\begin{array}{r}11 \\
16 \\
6 \\
17\end{array}$ & $\begin{array}{l}21 \\
40 \\
16 \\
13\end{array}$ & $\begin{array}{r}16 \\
14 \\
6 \\
32\end{array}$ & $\begin{array}{l}48 \\
70 \\
28 \\
62\end{array}$ \\
\hline Total ... & $\ldots$ & 50 & 90 & 68 & 208 \\
\hline
\end{tabular}

hundred and thirty-seven were seen within a few days of the acute incident and of these seven died $(5 \%)$ and 62 developed oesophageal strictures (46\%). The remaining 71 patients had established oesophageal strictures following injury sustained from weeks to years before admission to our wards. This paper deals with the 133 patients with strictures caused by caustic soda who have been treated in the thoracic surgical wards of the Johannesburg and Baragwanath Hospitals.

It is not intended here to discuss treatment in any detail, but clinical, radiological, and pathological findings will be presented and a classification of strictures will be submitted. The literature is poor in systematic descriptions of strictures which follow the ingestion of corrosives. It is believed that rational treatment must be based upon an accurate assessment of the type and severity of stricture, and it is hoped that this communication provides that basic need.

\section{Types and Classification of Strictures}

A corrosive stricture may be defined as a fibrotic narrowing of the oesophageal lumen which may or may not be lined by intact epithelium and which follows the ingestion of a corrosive substance. The severity of the stricture depends upon two factors: (1) the longitudinal extent of fibrosis, and (2) the density of fibrosis.

It is possible to differentiate two distinct types of stricture with intermediate gradations, namely, annular strictures (Figs. 1, 2, and 4) and tubular strictures (Figs. 5, 7, and 8).

For clinical convenience four grades of stricture have been defined.

Grade 1.-The fibrosis is confined to less than the complete circumference of the oesophagus and is limited in extent to a short, usually linear segment (Fig. 1). These strictures never produce sufficient narrowing to cause dysphagia, and are frequently accompanied by strictures of higher grade elsewhere.

GrADE 2.-These annular strictures have an appearance as of a string constricting the oesophagus (Fig. 2). They follow momentary contact of caustic with mucosa and the fibrosis is confined to the mucous and submucous layers (Fig. 3). They are usually elastic and have little tendency to progressive narrowing. They never cause dysphagia but may be the site of food impaction.

A grade 2 stricture can be predicted if weekly oesophagoscopic inspection during the early stages (Marchand, 1955) shows complete circumferential ulceration which heals within three weeks of injury. Because of the limited damage, regeneration of epithelium is rapid and fibrosis is minimal.

GraDE 3.-The stricture is dumb-bell shaped, the waist being the site of maximum narrowing and its length is limited, arbitrarily, to less than half an inch (Fig. 4). The walls are usually densely fibrotic and the lumen is often tortuous and may be narrowed to a thread. Fibrosis usually penetrates through the muscularis mucosae into the outer muscle coats. 

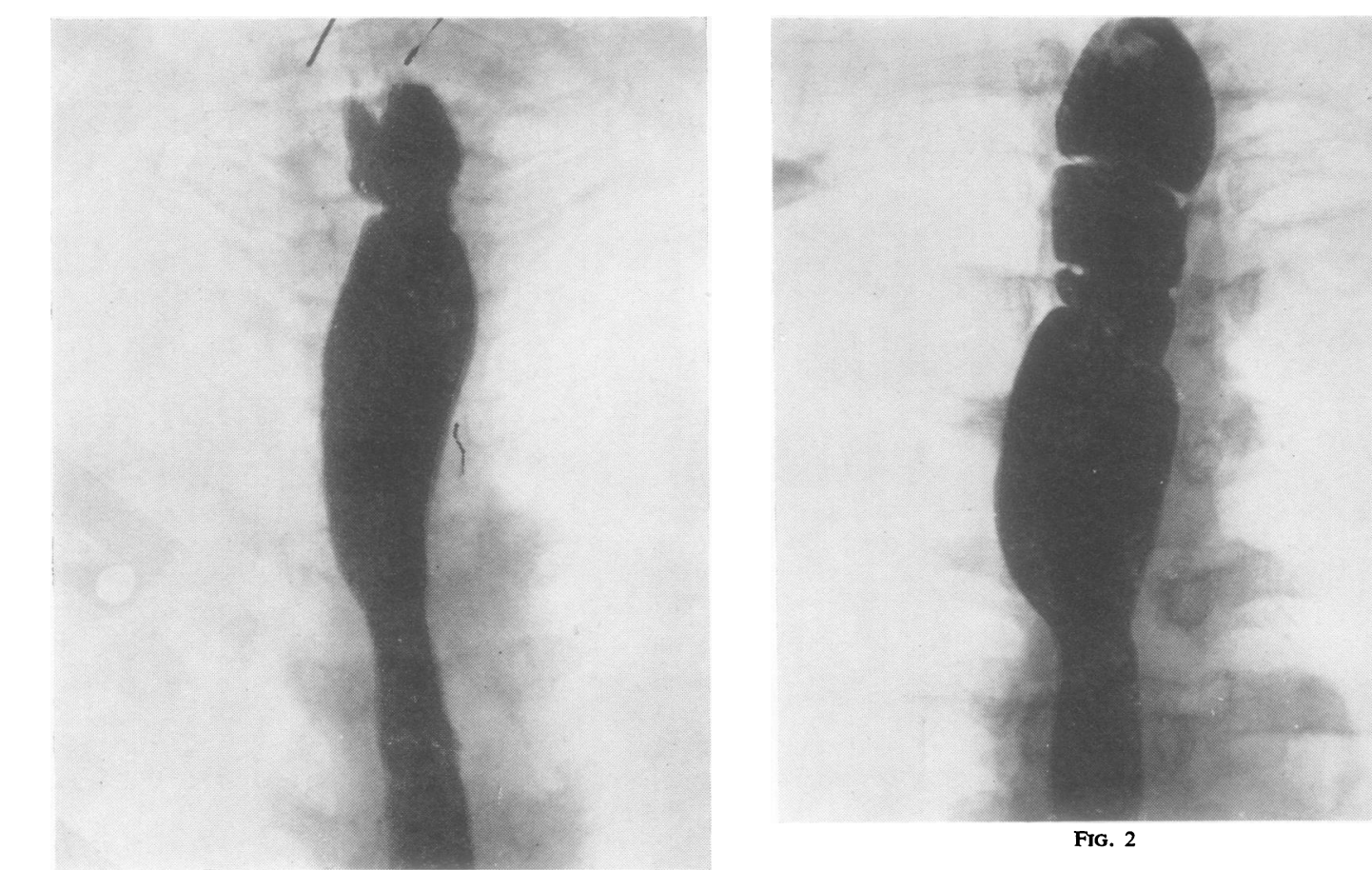

FIG. 2

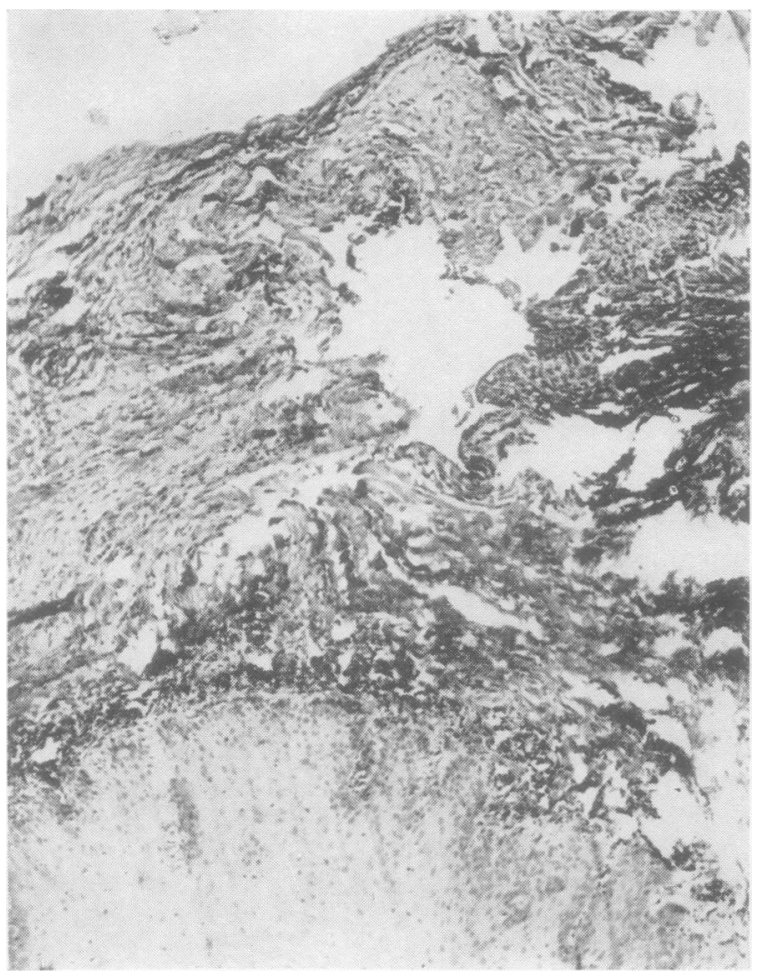

FIG. 3 


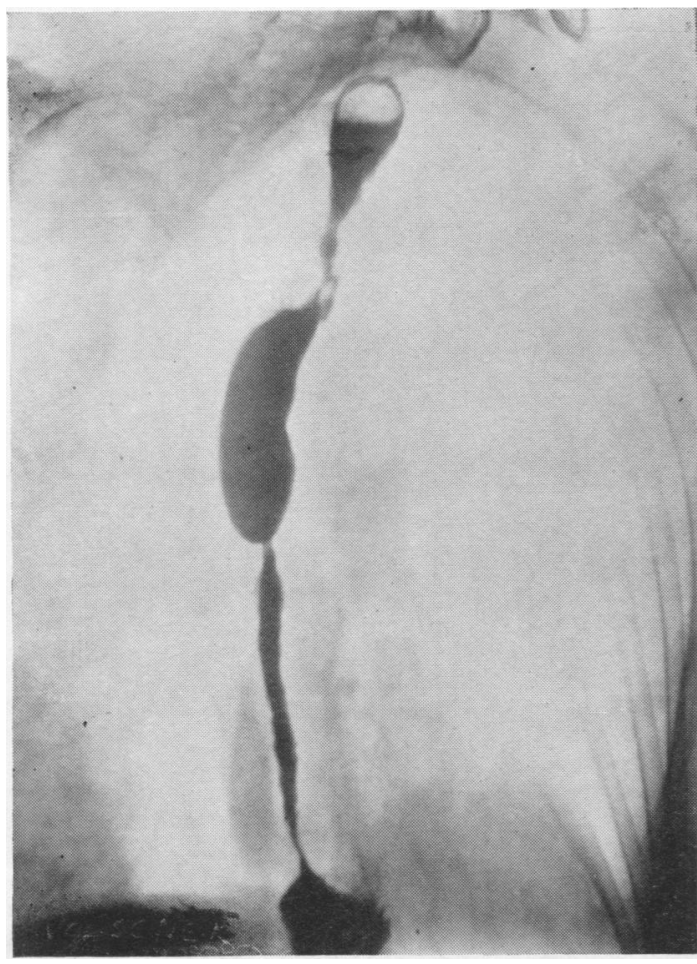

Fig. 5

Fig. 1.-Grade 1 stricture at the thoracic inlet. There is also a grade 4a stricture which begins at the level of the aortic arch.

Fig. 2.-Multiple grade 2 strictures of the upper thoracic oesophagus. These are associated with a retrocardiac tubular stricture (grade 4b).

FIG. 3.-Microscopic section of a grade 2 stricture obtained by endoscopic biopsy. The stratified epithelium has regenerated, but the submucosa is extensively fibrosed.

Fig. 4.-Solitary grade 3 stricture situated at the thoracic inlet.

FIG. 5.-Grade 4 strictures situated in the cervical and retrocardiac portions of the oesophagus. There is a false passage arising from the upper stricture.

FIG. 6.-Barium radiograph of a grade 4a stricture demonstrating the mobility of the strictured oesophagus (absence of perioesophageal adhesions). This patient sustained injury in childhood and at the age of 33 was admitted with a tuberculous pyopneumothorax. The right-sided empyema has displaced the oesophagus to the left.

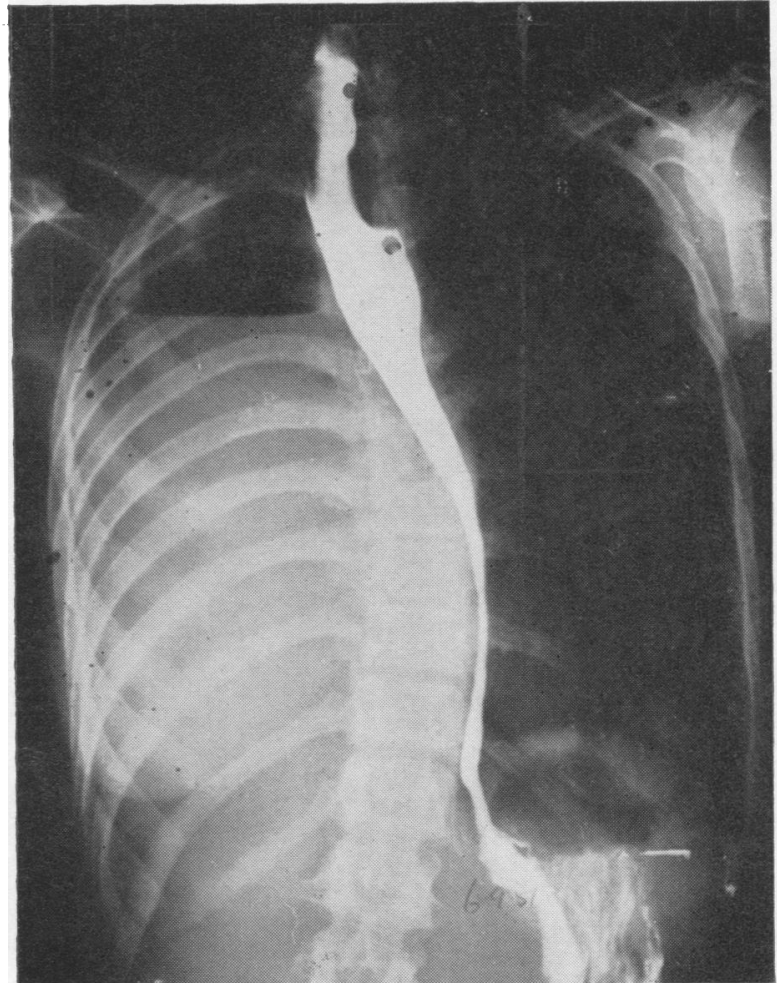

FIG. 6

These strictures are to be expected when circumferential ulceration, limited in length, is found by oesophagoscopy to persist for more than three weeks after the acute injury (Marchand, 1955).

Grade 4.-This grade includes all tubular strictures of more than $\frac{1}{2}$ inch in length (Fig. 5). The depth of penetration of fibrosis varies widely. It may extend through all the coats and cause perioesophageal adhesions or may be confined to the mucous layers so that, from the outer aspect, the area of stricture may look and feel quite normal. The greater the penetration the denser the stricture and the more narrow the lumen. When the mucosa has been entirely denuded over a long segment complete regeneration is impossible and the stricture is lined by granulation or fibrous tissue (Fig. 7).

The grouping of strictures into four grades has been of great assistance in regimenting one's impressions as to prognosis and treatment, but a classification based only on the length of the stricture does not include all the important factors. The main failing of such a grouping is that the density of the scar is not considered. This criticism cannot be applied to grade 1 and 2 strictures, as they are due to superficial corrosion, and fibrosis is never 

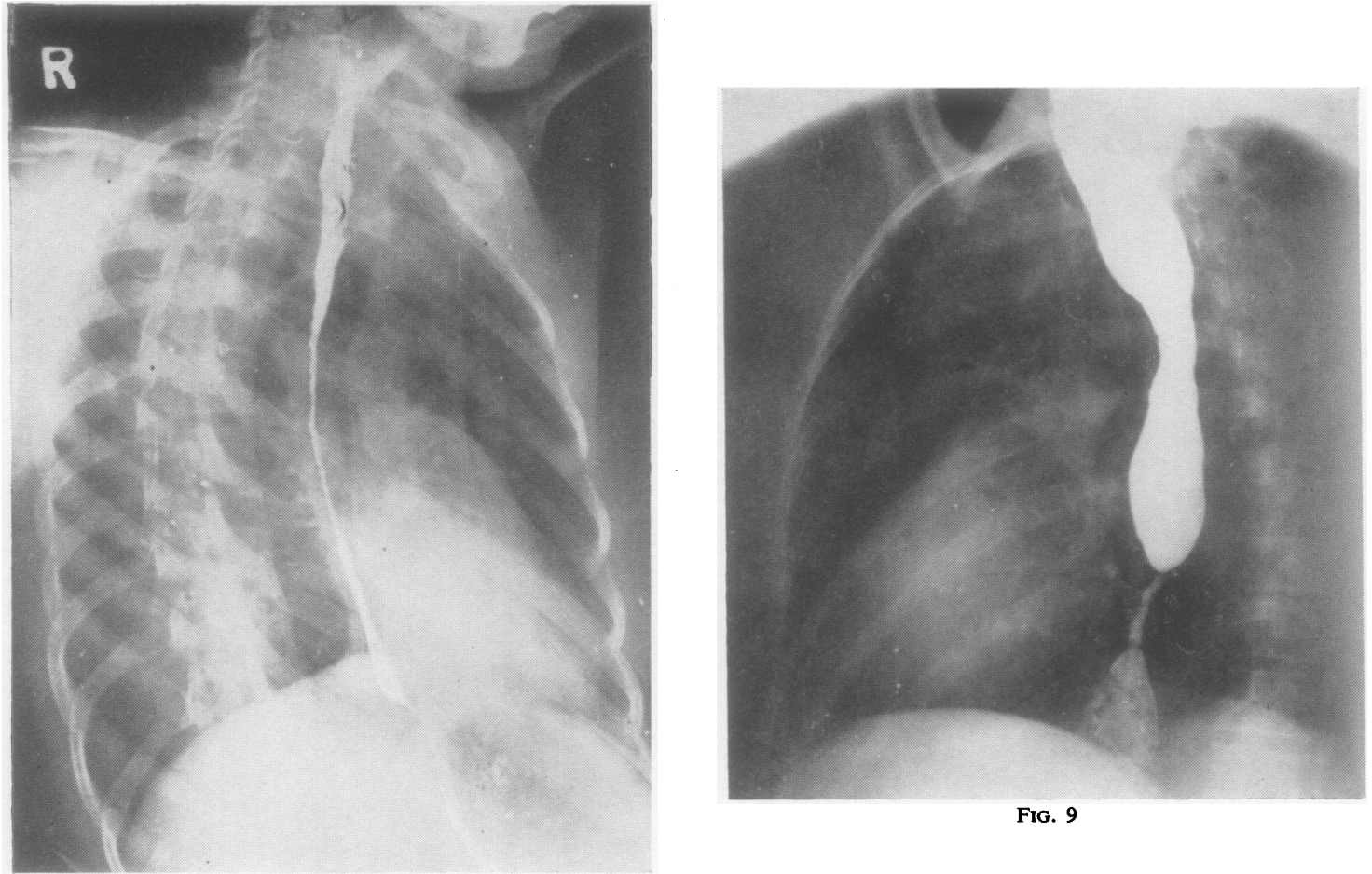

Fig. 9

FIG. 8

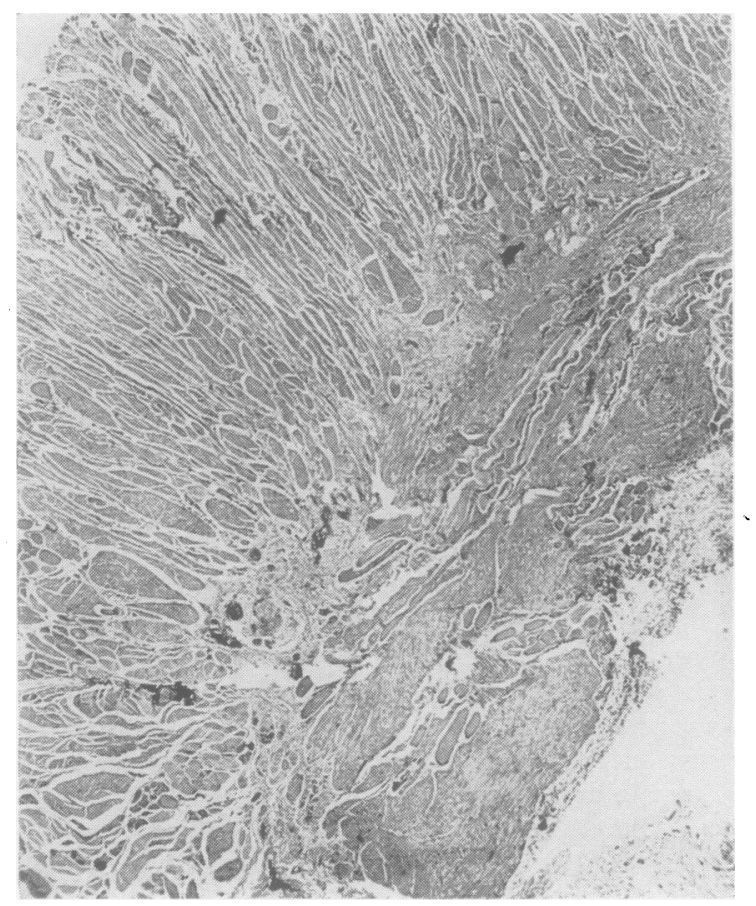

FIG. 7.-Microscopic section of grade $4 \mathrm{~b}$ stricture removed during operation of oesophago-gastrostomy. Injury was sustained 18 months previously, yet the lumen is lined only by fibrous tissue. The fibrosis extends through the whole thickness of the oesophagus $(\times 60)$.

Fig. 8.-Grade $4 \mathrm{~b}$ stricture involving almost the whole oesophagus. The lumen is reduced to a thread and repeated dilatations have $N$ failed to effect progress.

Fig. 9.-Short grade 4b stricture demonstrated by means of the regurgitation technique. The oesophagus above the stricture $\stackrel{C}{-}$ has been filled with swallowed barium while the stricture itself and the small pouch of oesophagus beyond it have filled with : barium regurgitating from the stomach. 
a prominent feature. Grade 3 strictures are the result of penetrating circumscribed corrosion, hence grade 3 implies specifically a dense localized stricture. Grade 4 strictures, though frequently densely fibrotic, are not necessarily so, particularly when a dilute solution of caustic soda has been the cause. It is the grade 4 strictures which provide the greatest therapeutic problems and it has been found helpful further to subdivide them into two subgroups.

Grade $4 a$.- These include all grade 4 strictures having little tendency to progressive narrowing. The fibrosis is confined to the superficial layers and peri-oesophageal adhesions never occur (Fig. 6). The subgrade is judged by the slight resistance offered to efforts at dilatation and by the fact that, once dilated, the lumen maintains its stretched calibre for some time. This ability to maintain dilatation is measured from week to week.

Grade $4 b$.-Tubular strictures with densely fibrotic walls, peri-oesophageal adhesions, and marked luminal narrowing are grouped as grade $4 \mathrm{~b}$ (Fig. 8). They are difficult to dilate and, once dilated, tend to contract rapidly, so that weekly dilatations may fail to efiect progress. In such cases the strictures are usually lined by fibrous tissue, the gap being too great to be bridged by the regenerating epithelium (Fig. 7).

\section{The Recognition of Grades of Stricture}

If a system of grading is to be of clinical value it is essential to possess precise methods of determining the length of the strictures. The following methods may be used:

OESOPHAgosCoPy.-The passage of an olivetipped bougie into the strictured lumen imparts a sense of resistance to the operator, and, by sensing variations in grip, it is possible to make a rough estimate of length. A difficulty is that tubular strictures seldom have a uniform calibre throughout, and, as the size of the bougie is governed by the narrowest part of the stricture, entry into a wider segment may give a false impression that the stricture has been traversed. This error can be rectified by first dilating the stricture and only assessing the length with the largest bougie. For the purpose of measuring length no reliance is placed on this method in practice, but other vital information can be gained. The resistance sensed during dilatation is taken as a criterion of density, and fixity of the oesophagus can be determined by manipulating the beak of the instrument. An oesophagus which cannot be displaced laterally by such manipulation is fixed by peri-oesophageal adhesions which only exist in grade 3 or $4 b$ strictures.
RADIOLOGY.-If the patient is given barium to swallow it is possible to visualize the beginning of tight tubular strictures with the most haphazard technique. However, grade 1 and 2 strictures, particularly when situated in the upper oesophagus, may be difficult to demonstrate because of the rapid forcible passage of barium. Furthermore, as mentioned by McKinney (1923), narrow strictures may allow so little barium to pass through that the normal oesophagus beyond fails to fill and the trickle of barium entering the stomach gives the appearance of a longer stricture than is actually prejent. A technique has been developed which overcomes these difficulties and enables absolute measurements to be made. The method entails increasing the intra-abdominal pressure so that the force of swallowing, acting against the high intragastric pressure, causes the oesophagus to distend and any rigid or relatively indistensible segments of the oesophagus are outlined. This is accomplished by inflating a rubber balloon, placed on the abdomen and fixed by a tightly laced body bandage extending from pubis to sternum, to a pressure of $60 \mathrm{~mm}$. of mercury. The method has been described and illustrated in a previous paper (Marchand, 1952). A further advantage is that if the stomach is already filled with barium, either by mouth or via the gastrostomy tube, the act of swallowing against the high abdominal pressures may initiate regurgitation of the stomach contents into the oesophagus. The freshly swallowed barium outlines the upper limit of the stricture and the regurgitant barium outlines the lower (Fig. 9).

\section{The Appearances of Strictures at Oesophago- SCOPY}

In grade 1 and 2 strictures the overlying mucosa is often mobile and normal in appearance, and the instrument may be passed without the manipulator even detecting the presence of the stricture. Where narrowing is sufficient to bar advance it is always possible to dilate the strictures so as to permit the introduction of a smaller oesophagoscope.

Grade 3 and 4 strictures always prevent the passage of the oesophagoscope and only the stricture face can be visualized. In these cases dilatation should not be attempted in the absence of satisfactory oesophagographs.

The face of an established stricture is usually lined by healthy mucosa and the opening of the lumen may be centrally or eccentrically placed. The situation of the opening depends on the degree of fibrosis at different parts of the circumference. If fibrosis is equally distributed the orifice remains central, but when it is most severe in a part of the 


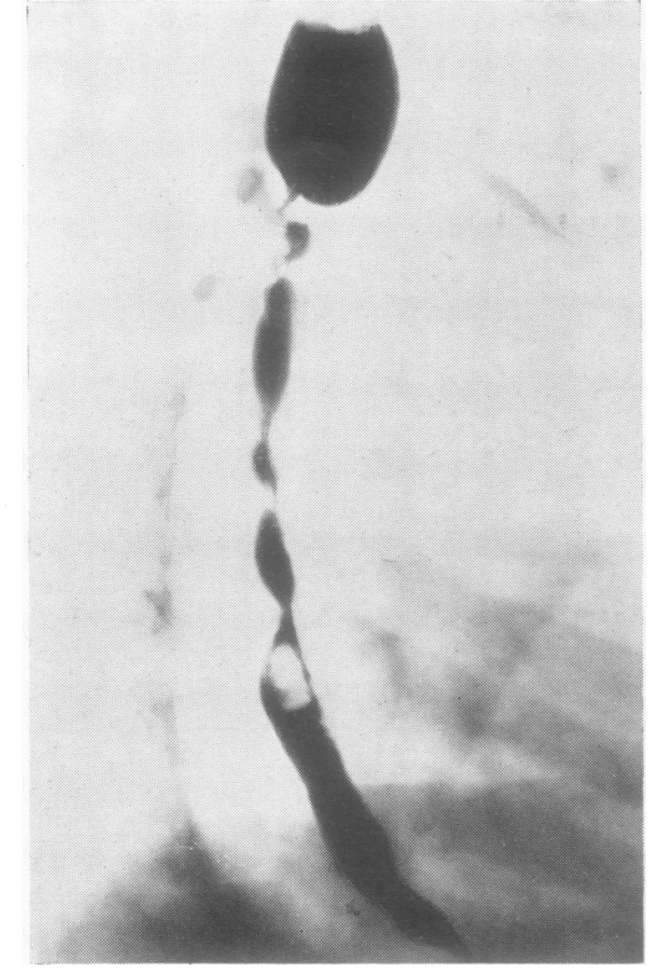

Fig. 10.-Barium radiograph demonstrating extreme tortuosity of the lumen. The orifice at the origin of the stricture is eccentrically placed. The proximal oesophagus is dilated and bowl-shaped, but distally) the normal calibre of the oesophagus has the appearance of an inverted funnel. Antegrade instrumental dilatation of this"stricture would be an extremely /hazardous manœuvre.

wall, then the orifice is drawn towards that part (Fig. 10). Folds of mucosa or irregularities in fibrosis may give the appearance of several ostia and some time may be spent before the actual entrance to the lumen is found. The opening may be reduced to the size of a pin-hole and may be covered by a mucosal fold to give the appearance of a total obstruction. As a general rule the stricture face is comparatively smooth and, as Billroth pointed out in 1883 , dilatation of the oesophagus proximal to the obstruction makes the origin of strictures bowl-shaped whilst the lower end, due to the undilated distal oesophagus, is funnel-shaped (Fig. 10).

\section{IMPERMEABLe STRICTURes OF THE Oesophagus}

On 14 occasions it was impossible to negotiate strictures with bougies, but in only two instances was complete obstruction confirmed by radiography (Fig. 11). The remainder were shown to have markedly narrowed and tortuous lumina (Fig. 10).

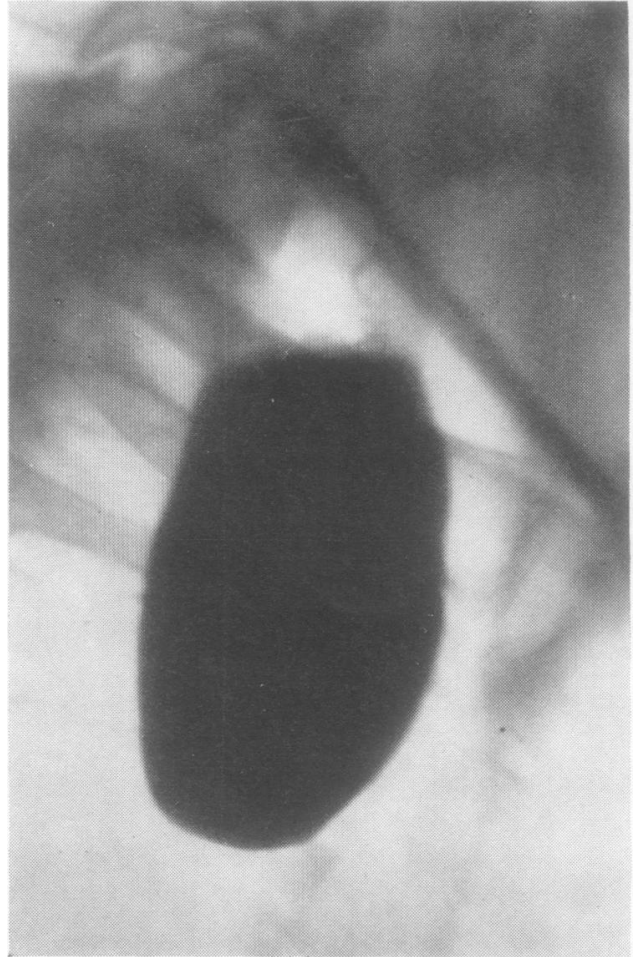

Fig. 11.-Total obstruction caused by a grade $4 \mathrm{~b}$ stricture beginning at the level of the aortic arch.

Guisez (1922) had experience of $2 \%$ solid strictures out of 185 cases, an incidence closely comparable with ours. Total obstructions are dangerous, even when an efficient gastrostomy has been performed. One of our patients died as a result of inhaling food and secretions. Even with a pin-hole lumen the patient may be able to swallow saliva. Apparently excessive salivation accompanying a stricture is a sign of very advanced narrowing of the oesophagus.

\section{INCIDENCE OF STRICTURES}

In the total series of 133 cases, 92 were adults and 41 were children (Table II). There were 82 grade 4 strictures $(61 \%)$ of which 66 or $50 \%$ of the total were severe grade $4 \mathrm{~b}$ strictures. There was a higher proportion of grade $4 \mathrm{~b}$ strictures among the children than among the adults $(61 \%$ and $45 \%)$.

In this series solitary strictures were rare and the three minor grades were usually associated with more extensive strictures in the lower oesophagus. There were only 18 instances where solitary grade 1 , 2 , or 3 strictures were found $(14 \%)$. There were $15(13 \%)$ cases where a single extensive grade 4 stricture was present alone. Even if these are included as solitary strictures only $27 \%$ of cases had localized involvement of the oesophagus. 
TABLE II

ANALYSIS OF ALL PATIENTS TREATED FOR CORROSIVE OESOPHAGEAL STRICTURES ACCORDING TO AGE AND SEVERITY OF STRICTURE*

\begin{tabular}{c|c|c|c}
\hline $\begin{array}{c}\text { Grade of } \\
\text { Stricture }\end{array}$ & $\begin{array}{c}\text { Total } \\
\text { No. }\end{array}$ & Adult & $\begin{array}{c}\text { Child } \\
\text { (Under 14 Years) }\end{array}$ \\
\hline 1 & 13 & 9 & 4 \\
2 & 17 & 13 & 4 \\
3 & 21 & 18 & 3 \\
$4 \mathrm{a}$ & 16 & 11 & 5 \\
$4 \mathrm{~b}$ & 66 & 41 & 25 \\
\hline Total .. & 133 & 92 & 41 \\
\hline
\end{tabular}

* Where multiple strictures were present the grade is reckoned as that of the most severe.

This is in variance with most other reports. Martin and Arena (1939) quote an incidence of $70 \%$ solitary strictures, von Hacker (1889) $68 \%$, and Kernodle, Taylor, and Davison (1948) had $82 \%$ solitary strictures in their series. It is felt that the apparent discrepancy is largely accounted for by the differences in the methods of diagnosis. Without a method of oesophageal distension it is impossible to determine the precise distribution of strictures.

\section{Sites of Strictures}

Crowe (1944) reports a series of 37 corrosive strictures of which $81 \%$ were solitary and of these $52 \%$ were cervical. Vinson (1927) maintains that the majority of strictures are in the upper oesophagus and Hodge and Scharfe (1937) concur. Jackson and Jackson (1945) cite the level of the left bronchus as the commonest situation, then the crico-pharyngeus sphincter, and finally the level of the diaphragmatic hiatus. Leegaard (1945), on the other hand, found that the lower oesophagus was most frequently involved.

Table III lists the sites of strictures found in this series. One hundred and fifty-four occurred at or below the level of the aortic arch and 120 above. More important, however, is the fact that,

TABLE III

LEVELS OF STRICTURES IN THIS SERIES*

\begin{tabular}{c|c|c|c|c|c|c}
\hline $\begin{array}{c}\text { Crico- } \\
\text { pharyngeus }\end{array}$ & Cervical & $\begin{array}{c}\text { Thoracic } \\
\text { Inlet }\end{array}$ & $\begin{array}{c}\text { Upper } \\
\text { Thoracic }\end{array}$ & $\begin{array}{c}\text { Aortic } \\
\text { Arch }\end{array}$ & $\begin{array}{c}\text { Retro- } \\
\text { cardiac }\end{array}$ & $\begin{array}{c}\text { Pyloric } \\
\text { or } \\
\text { Gastric }\end{array}$ \\
\hline 11 & 50 & 40 & 19 & 86 & 64 & 10 \\
\hline
\end{tabular}

* With grade 4 strictures the upper end is listed.

though 22 grade $4 \mathrm{~b}$ strictures began above the level of the aortic arch, only four were sited essentially in the upper oesophagus, so that in 62 cases $(95 \%)$ the greater part of the $4 \mathrm{~b}$ strictures were in the lower oesophagus. In the occasional case where the maximal damage was to the upper oesophagus it was usual to learn that solid caustic soda had been swallowed.

The results of this survey refute Jackson's contention that the sites of physiological narrowing are the most vulnerable to corrosive injury. Indeed it is rare for the terminal oesophagus at hiatus level to be involved and even the longest strictures usually fail to involve the final 1 or $2 \mathrm{~cm}$. of oesophagus (Figs. 12, 10, 9, 8, 5). It is the region from here to the level of the aortic arch which suffers

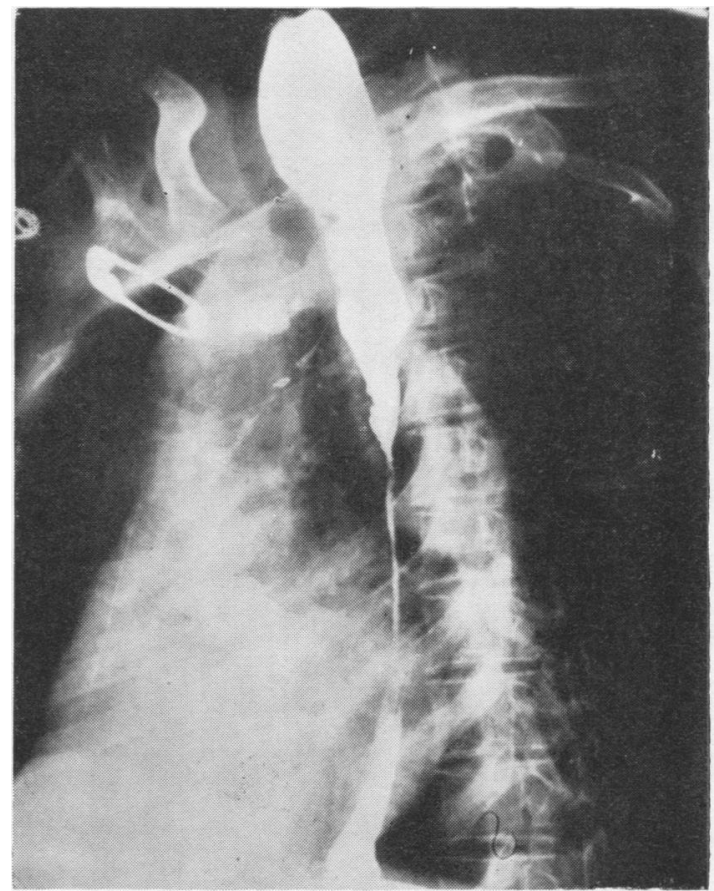

FIG. 12.-Grade 4b retrocardiac stricture showing unaffected terminal oesophagus which was filled by inducing regurgitation from the stomach into which barium had been introduced through a gastrostomy opening.

most severely. This distribution of injury can, it is believed, be explained on the basis of the mechanics of swallowing. Passage is rapid through the upper oesophagus and slow below the aortic arch so that contact of the corrosive with the gullet is momentary in the cervical portion but prolonged in the infra-aortic portion. It is more difficult to explain the comparative immunity of the terminal oesophagus. It is possible that the spasm of the "cardia" which occurs in response to the corrosive injury (Marchand, 1955) may involve this segment and, when it does relax, passage through it is rapid.

\section{Growth of STRICtures}

Eight adults in this series sustained injury in childhood and three children have been followed 


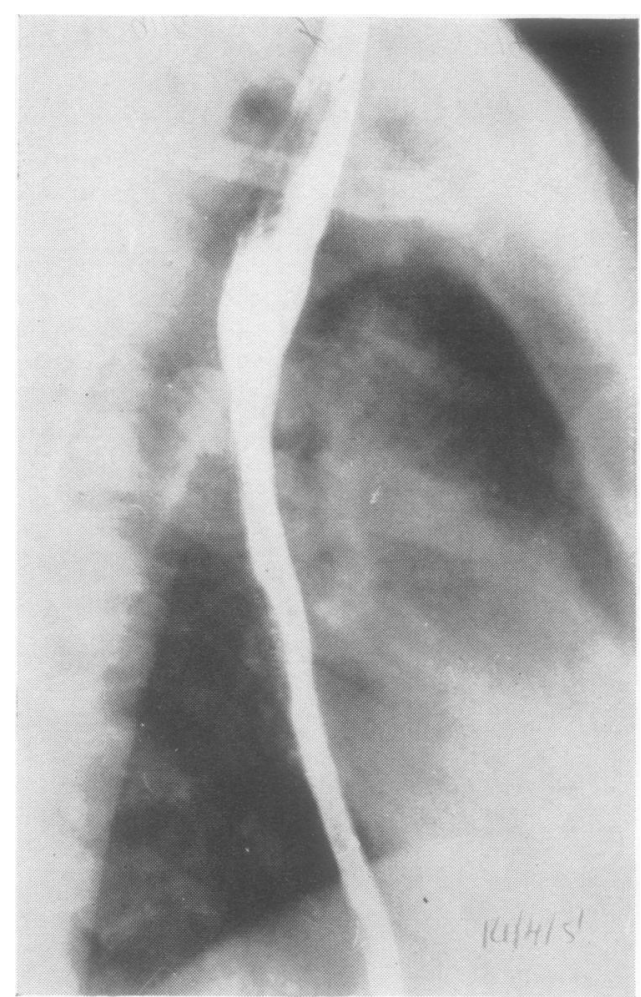

FIG. 13

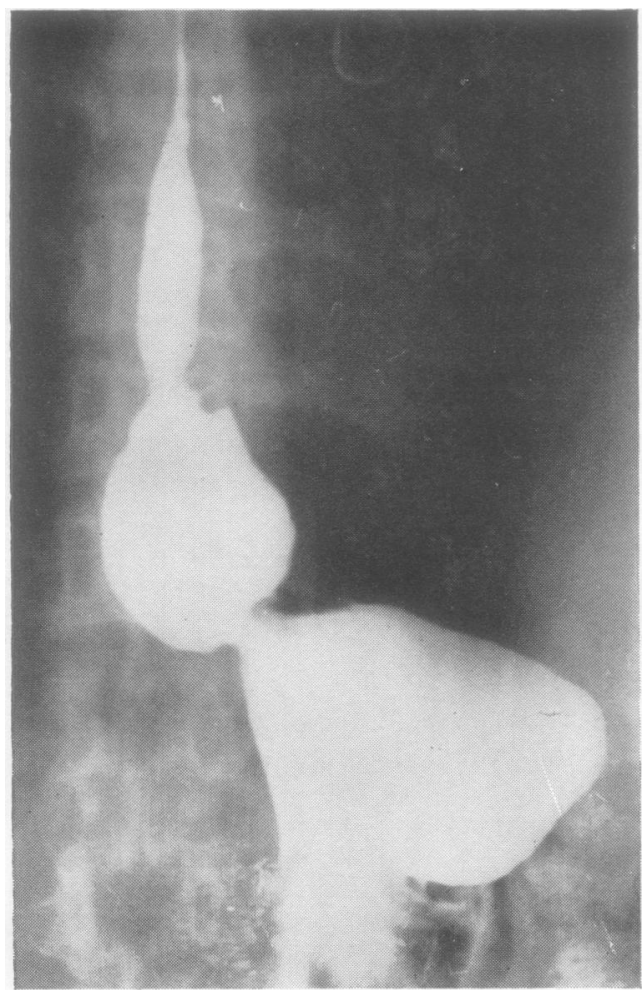

FIG. 15

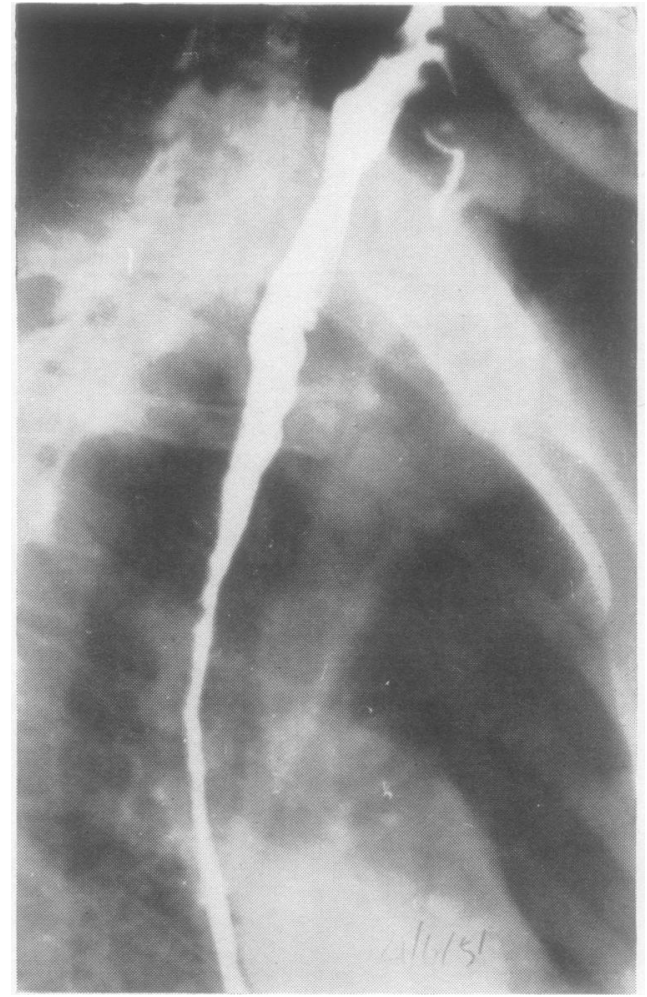

FIG. 14

FIG.!13.-Barium radiograph six days after the patient had swallowed a concentrated solution of caustic soda. The lower oesophagus was immobile and narrowed, denoting severe oesophageal injury (Marchand, 1955). No evidence of a hiatus hernia can be detected.

FIG. 14.-Barium radiograph two months after injury. A long grade $4 \mathrm{~b}$ stricture has developed.

FIG. 15.-Appearance two years and four months after injury. The stomach was filled with barium through a gastrostomy tube and retrograde filling of the oesophagus was accomplished by means of the abdominal compression bag. There is a large hiatus hernia which was found to be irreducible at operation due to true " shortening" of the fibrosed oesophagus. 
for five years or more after swallowing caustic soda. From these cases some ideas on the growth of a strictured oesophagus have been formulated.

It is of interest that in no instance where injury was sustained in childhood has the stomach been drawn up into the chest even though long strictures have been present. Judging by the present length of some of the strictures which began in early childhood (Fig. 7) it would appear that fibrosed segments of the oesophagus can increase in length as the body grows. On the other hand, it has been noted with children that the upper end of the strictures has become progressively further from the incisor teeth whilst oesophagographs have shown that the strictures have not increased in absolute length. However, in these cases no very severe stricture was present so that conclusions are difficult to draw.

\section{Longitudinal Shrinkage of Strictures}

A case of great interest is that of a coloured woman aged 22 who swallowed a concentrated solution of caustic soda on April 8, 1951. A barium swallow performed six days after injury showed an immobile spastic oesophagus (Fig. 13) (Marchand, 1955). On June 4, 1951, a long grade $4 b$ stricture was visualized (Fig. 14), but the patient refused treatment and absconded. She occasionally visited other hospitals, but next appeared in our Outpatient Department on August 20, 1953, two years and four months after her initial injury. She was dehydrated and emaciated and an emergency gastrostomy was performed. On September 10 a regurgitation barium oesophagograph with the abdominal compression bag showed that a large hiatus hernia was present (Fig. 15). Study of the previous radiographs reveals no sign of a hernia and it appears as if the stricture had contracted during the two years and dragged the stomach into the chest. This is the only case with such a course, and in the absence of previous distension barium studies it is just possible that the hernia was present before the injury.

\section{Pyloric Stenosis}

The stomach is probably always involved to some extent whenever more than a sip of caustic soda has been swallowed. Necropsies on the seven acute fatal cases showed the stomach to be severely corroded and in two instances the whole thickness of the organ had necrosed. However, amongst the survivors clinical evidence of gastric fibrosis is rare. There have been seven cases of pyloric stenosis, two of diffuse gastric fibrosis, and one of hour-glass stricture in this series, an incidence of $7.5 \%$.
Strode and Dean (1950) collected the records of 140 cases of pyloric stenosis following corrosive poisoning, but few were due to caustic soda. Paul (1951) reported three cases due to concentrated solutions of mineral acids. We have seen five cases of hydrochloric acid poisoning, four of which developed pyloric stenosis. It is believed that the comparative immunity of the stomach to alkaline corrosion is due to the small quantities which reach it in patients who survive and to the gastric acidity which is able to neutralize these amounts before damage is done. Neutralization may be incomplete, but the solution is probably so diluted that only superficial damage is done. When massive amounts of any concentrated caustic are swallowed the gastric juices are overwhelmed and the stomach suffers accordingly.

It is interesting that the four patients with acid injuries only had mild oesophageal strictures while all the caustic soda cases were associated with severe oesophageal strictures. Paul (1951) and Strode and Dean (1950) remark upon the infrequency of associated oesophageal strictures when acids are the cause, and ascribe this to rapid swallowing of the corrosive, if accidental because of the pain, if suicidal because of determination. It is difficult to believe that the rate of passage through the oesophagus can be voluntarily controlled except by swallowing a large amount of fluid in a continuous stream (as in draining a tankard of beer), a feat beyond the powers of the most determined suicide with a caustic beverage. Rather, it is believed that the action of the mineral acids is less corrosive than that of caustic soda and that in the time it takes for the acid to pass through the oesophagus less penetrating injury is caused.

It must be remembered that large volumes of concentrated corrosives are invariably fatal and that in the survivors probably very little indeed enters the stomach. Small amounts of alkaline caustics are partially or completely neutralized by the acid gastric juices, but the mineral acids continue their action with unrestricted intensity. Testa (1938) has shown that the introduction of barium impregnated with caustic into the stomach causes prolonged pyloric spasm. This must permit any active corrosive to exert its harmful effects over a long period.

The symptoms of pyloric stenosis usually come on rapidly. Four of our patients vomited copiously from the start. The case of hour-glass stomach had no gastric symptoms and was found incidentally during barium examination. The remaining cases developed symptoms within three weeks of injury. Schulenburg (1941) has drawn attention to this 
rapid development of symptoms and states that they usually appear within the first four weeks.

Moynihan (1926) likened the pylorus and the antrum, in cases of corrosive pyloric stenosis, to the normal cervix and uterus. This is an apt comparison, the walls of the stenosed area being thick and unyielding, and the lumen through the narrowed segment may be reduced to a thread. The body of the stomach may be grossly dilated, as in five of our cases, but in the remainder the walls of the whole organ were fibrosed and little distension was possible. In two cases the stomach was contracted, the whole organ being thickened and fibrosed. In all these patients, peritoneal adhesions were absent and the serosal coat of the stomach appeared uninvolved.

\section{Complications of Oesophageal Strictures}

The complications of oesophageal strictures, apart from malnutrition and the accidents of treatment, are few. Vinson (1927) has described malignant degeneration at the site of old corrosive injuries, but this has not occurred in the present series. One frequent complication is sudden total dysphagia due to impaction of food in the narrowed lumen. Fourteen patients have been admitted for this reason.

Patients who sense oesophageal discomfort go to great pains to avoid eating hunks of meat, sinew, orange pips, and bread-crusts, and restrict themselves to fluids, semi-solids, and soft foods which they are able to masticate thoroughly. A meal may be a laborious feat, but better that than the discomfort and pain of total oesophageal obstruction. On two occasions we have had to remove barium from strictures after thick barium paste had been used to outline the oesophagus.

Many of the patients admitted with impacted foreign material had widely patent strictures which produced no conscious hindrance to swallowing. After months or years of normal eating they had swallowed a fruit pip or an inadequately chewed piece of sinew or meat. In such cases the patients usually attempt to dislodge the offending morsel by manœuvres learnt by past experience to be effective, and often wait several days before admitting defeat.

Inhalation of food and secretions producing bronchopneumonias, atelectasis, lung abscess, and empyema is not uncommon where treatment has been neglected. These complications only occur with tight strictures and are the usual causes of death in inadequately treated cases.

\section{Discussion}

In addition to these 133 cases of simple strictures following the ingestion of caustic soda we have seen four cases due to ammonia, five due to hydrochloric $\frac{\omega}{\vec{D}}$ acid, three due to washing soda, and one each due $\triangle$ to potassium permanganate and lysol. These ${ }^{\circ}$ latter cases are not included in this paper, but, $\vec{\circ}$ apart from being on the average less severe in nature than those due to caustic soda, they do not $\vec{\omega}$ differ in detail and have been assessed according to the principles outlined here.

It is felt that the grouping of strictures into $\vec{\circ}$ grades would provide different workers with a basis whereby to compare the results of treatment. $\vec{v}$ The severity of strictures varies so widely that very little information is conveyed simply by stating that a certain number of oesophageal strictures $\vec{c}$ have been successfully treated by one or other $\subsetneq$ method. It is the severe tubular strictures, here ${ }^{\infty}$ grouped as grade $4 \mathrm{~b}$, which provide the problems $\vec{\oplus}$ and difficulties of treatment.

The system of grading has also proved useful in indicating the probable treatment needed for a particular case. Of course every patient has to be assessed individually, the age and personality having a profound bearing upon the choice of $\stackrel{\mathbb{Q}}{\propto}$ method, but generalizations can be made. Grade $1 \overrightarrow{\overrightarrow{0}}$ strictures never require any active treatment as they 3 never contract sufficiently to produce disability. Grade 2 strictures may require occasional dilata-c tions, particularly during the early stages, but apart from the dangers of food impaction they never give rise to serious concern. Grade 3 strictures, $\stackrel{x}{x}$ being dense though localized, always require treat- $\frac{0}{3}$ ment during the initial stages. Occasional difficulty may be experienced in finding the way through these $ᄋ$ strictures, but we have never failed eventually to accomplish this by one means or other and sub-음 sequently to effect adequate dilatation. Once $>$ dilated it should be possible to maintain the lumen by self-bouginage, but here the unpredictable factor $N$ of the patient's temperament takes a hand. Onthree occasions with suitable localized strictures 0 (two children and one adult) it was felt that local $\mathrm{N}$ excision or oesophagoplasty was preferable to interminable dilatations under anaesthesia and theo operations were undertaken. In one case this was entirely successful, but the others have recurred.? It is now felt that local operations are very seldom ${ }^{0}$ indicated and we persist with conservative measures $\frac{\vec{D}}{\mathbb{D}}$ with all grade 3 strictures. Inevitably the time $\stackrel{?}{?}$ comes when frequent dilatations are no longer $\mathbb{Q}$ necessary and the management becomes less burden- 0 some for both patient and surgeon. 
Grade $4 \mathrm{a}$ strictures can always be dilated, and the routine of dilatation under anaesthesia until an adequate lumen is attained and maintenance of the lumen by self-bouginage usually ensures a satisfactory outcome. Should the patient fail to persevere with this then occasional readmission to hospital for dilatation under anaesthesia is necessary.

Grade $4 \mathrm{~b}$ strictures, unfortunately the commonest in this series, provide a far more difficult problem. With intelligent cooperative and determined patients dilatation should be attempted. A little less than half of all the grade $4 \mathrm{~b}$ strictures have been controlled by this means, but treatment is long and arduous. Where the patient has been neglected in the early stages the failure rate is high, but even amongst those who have been treated in our unit from the beginning $41 \%$ have subsequently required major reconstructive surgery.

Once the stricture is more than several inches in length epithelium can never bridge the gap, and, no matter how determined the patient or how adequate the early management, conservative measures will never succeed. We have now had to operate upon 35 patients with grade $4 \mathrm{~b}$ strictures in order to reconstruct a pathway from mouth to stomach.

The days are now perhaps past when it was true to say that those who live by the bougie die by the bougie (to misquote Trousseau), but none the less the mortality from caustic soda poisoning over the years remains appreciable. How much better it would be if the problem of treating grade $4 \mathrm{~b}$ strictures would never arise! In these days of cheap, efficient detergents it seems senseless and even culpable to continue to permit the free sale of caustic soda for household use.

\section{Summary AND CONCLUSIONS}

One hundred and thirty-three cases of oesophageal stricture following the ingestion of caustic soda have been treated in six years.

It is believed that classification of the types of stricture is essential in order to decide on the appropriate treatment and to judge its efficiency. A classification based upon the length and severity of the strictures is here presented.

It has been found that the most severe strictures occur in the lower oesophagus. Solitary localized strictures are rare and consequently restricted operative intervention is usually out of the question. Though the worst strictures are usually retrocardiac in position it is usual to find that the upper oesophagus is also affected. An accurate assessment of the extent of oesophageal involvement must be made and it is believed that this is best accomplished by the method of distending the oesophagus with barium.

Ten cases of gastric fibrosis have been found. Nine of these were symptomatic. All these patients had severe abdominal pain during the acute stage and vomiting of food appeared within three weeks of injury. The relative rarity of gastric fibrosis is noted. It is believed that very little caustic enters the stomachs of those who survive and that with alkaline corrosives the gastric juices are usually able to neutralize these amounts.

All the patients in this series were admitted under Mr. L. Fatti, Head of the Thoracic Surgery Unit. Both he and Mr. G. R. Crawshaw have been intimately concerned with this work and many of their opinions have inevitably been incorporated in this paper. I wish to thank them both for allowing me to draw so freely from their experience. I wish also to thank Professor W. E. Underwood for encouraging this publication and helping in its production.

\section{REFERENCES}

Billroth, C. A. (1883). Allg. wien. med. Ztg., $28,141$.

Crowe, J. T. (1944). Amer. J. Dis. Child., 68, 9.

Guisez, J. (1922). Gaz. Hôp., Paris, 95, 295.

Hacker, V. von (1889). Uber die nach Verätzungen entstehenden Speiseröhren-Verengerungen. Hölder, Vienna.

Hodge, G. E., and Scharfe, E. E. (1937). Canad. med. Ass. J., 37 . 541.

Jackson, C., and Jackson, C. L. (1945). Diseases of the Nose, Throat, and Ear, p. 711. Saunders, Philadelphia and London.

Kernodle, G. W., Taylor, G., and Davison, W. C. (1948). Amer. J. Dis. Child., 75, 135.

Leegaard, T. (1945). J. Laryng., 60, 389.

McKinney, R. (1923). J. Tenn. med. Ass., 16, 239.

Marchand, P. (1952). Brit. J. Radiol., 25, 476.

(1954). S. Afr. med. J., 28, 415.

- (1955). Ibid., 29, 195.

Martin, J. M., and Arena, J. M. (1939). Sth med. J., Bgham, Ala., 32, 286.

Moynihan, B. G. A. (1926). Abdominal Operations, 4th ed., Vol. 1, p. 342. Saunders. Philadelphia and London.

Paul, M. (1951). Lancet, 2, 1064.

Schulenburg, C. A. R. (1941). Ibid., 2, 367.

Strode, E. C., and Dean, M. L. (1950). Ann. Surg., 131, 801.

Testa, G. F. (1938). Radiol. med. Torino, 25, 17.

Vinson, P. P. (1927). Ann. Otol., St. Louis, 36, 40. 